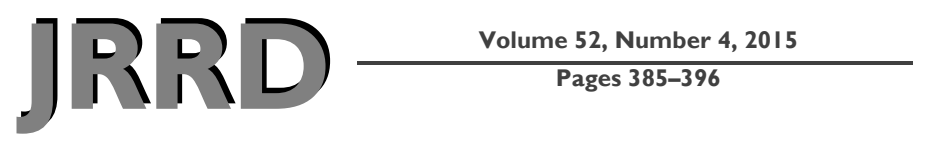

\title{
Effects of prosthetic limb prescription on 3-year mortality among Veterans with lower-limb amputation
}

\author{
Jibby E. Kurichi, MPH; ${ }^{1 *}$ Pui Kwong, MPH; ${ }^{1}$ W. Bruce Vogel, PhD $;{ }^{2-3}$ Dawei Xie, PhD; ${ }^{1}$ Diane Cowper Ripley, \\ PhD; ${ }^{3-4}$ Barbara E. Bates, MD $^{5}$ \\ ${ }^{1}$ Center for Clinical Epidemiology and Biostatistics, School of Medicine, University of Pennsylvania, Philadelphia, \\ PA; ${ }^{2}$ North Florida/South Georgia Veterans Health System (NF/SG VHS), Gainesville, FL; ${ }^{3}$ Department of Health Out- \\ comes and Policy, College of Medicine, University of Florida, Gainesville, FL; ${ }^{4}$ Department of Veterans Affairs (VA) \\ Health Services Research and Development/Center of Innovation on Disability and Rehabilitation Research, NF/SG \\ VHS, Gainesville, FL; ${ }^{5}$ Samuel S. Stratton VA Medical Center, Albany, NY; and Department of Physical Medicine and \\ Rehabilitation, Albany Medical College, Albany, NY
}

\begin{abstract}
Our objective was to determine the relationship between receipt of a prescription for a prosthetic limb and $3 \mathrm{yr}$ mortality postsurgery among Veterans with lower-limb amputation (LLA). We conducted a retrospective observational study that included 4,578 Veterans hospitalized for LLA and discharged in fiscal years 2003 and 2004. The outcome was time to all-cause mortality from the amputation surgical date up to the 3 yr anniversary of the surgical date. Of the Veterans with LLA, 1,300 (28.4\%) received a prescription for a prosthetic limb within $1 \mathrm{yr}$ after the surgical amputation. About $46 \%$ ( $n=2,086)$ died within 3 yr of the surgical anniversary. Among those who received a prescription for a prosthetic limb, only $25.2 \%$ died within 3 yr of the surgical anniversary. After adjustment, Veterans who received a prescription for a prosthetic limb were less likely to die after the surgery than Veterans without a prescription, with a hazard ratio of 0.68 (95\% confidence interval: 0.60-0.77). Findings demonstrated that Veterans with LLA who received a prescription for a prosthetic limb within 1 yr after the surgical amputation were less likely to die within 3 yr of the surgical amputation after controlling for patient-, treatment-, and facility-level characteristics.
\end{abstract}

Key words: amputation, lower-limb amputation, methods, mortality, outcomes, prosthesis, prosthetic limb, retrospective studies, time-dependent covariate, Veterans.

\section{INTRODUCTION}

Lower-limb amputation (LLA) is a life-altering event, affecting the patient's quality of life and health as well as their functional, economic, and psychosocial status [1]. It has been shown that there is a decrease in social

Abbreviations: BIRLS = Beneficiary Identification Records Locator Subsystem, CI = confidence interval, CMS = Centers for Medicare and Medicaid Services, CNS = central nervous system, DME = Durable Medical Equipment, FY = fiscal year, HR = hazard ratio, ICD-9-CM = International Classification of Diseases-Ninth Revision-Clinical Modification, ICU = intensive care unit, ID = identification, LLA = lower-limb amputation, NF/SG VHS = North Florida/South Georgia Veterans Health System, NPPD = National Prosthetics Patient Database, PTF = Patient Treatment File, VA = Department of Veterans Affairs, VAMC = VA medical center, VHA = Veterans Health Administration.

*Address all correspondence to Jibby E. Kurichi, MPH; Center for Clinical Epidemiology and Biostatistics, School of Medicine, University of Pennsylvania, 907 Blockley Hall, 423 Guardian Dr, Philadelphia, PA 19104; 215-898-8490; fax: 215-573-2017. Email: jkurichi@mail.med.upenn.edu http://dx.doi.org/10.1682/JRRD.2014.09.0209 
participation, employment, and overall general functioning within the community following an amputation [2]. Comorbid conditions such as depression may set in, making it difficult for people to return to their normal activities postamputation [3]. In addition, families may be affected because they may view the amputation as a burden, forcing unwanted changes in their own lives such as modifying their work schedules or adjusting their living environment if the patient cannot return home safely without the changes [4]. Conversely, family members may become very overprotective and assist the person with the amputation such that the person may not achieve optimal functional recovery.

Rehabilitation can assist the person with an amputation to regain as much function as possible. One important component of rehabilitation is the prescription and receipt of a prosthetic limb for those who are able to use one [5]. A prosthetic limb could help improve mobility, potentially leading to better quality of life. Improved mobility can allow the prosthesis wearer to be more independent in performing activities of daily living, potentially requiring less assistance from another person. Patients who have had rehabilitation for prosthetic training have been shown to have higher levels of physical and cognitive functioning [6]. Even gains in low levels of physical independence achieved through rehabilitation showed improved 1 yr survival postsurgery among Veterans with LLA [7].

We previously demonstrated that younger Veterans, those with transtibial compared with transfemoral LLAs, and those initially evaluated with higher physical and cognitive abilities were more likely to receive a prescription for a prosthetic limb. Factors negatively influencing receipt of a prosthetic limb included admission to the hospital from extended care compared with home, numerous amputation etiologies, comorbidities, and undergoing certain procedures while hospitalized [8]. We also showed that older age, higher amputation level, more comorbidities, evidence of inpatient procedures for pulmonary and renal problems, central nervous system (CNS) procedures, treatment on an intensive care unit (ICU) or medical bed section (i.e., cardiology, pulmonary) compared with a surgical bed section (i.e., neurosurgery, thoracic surgery), and regional differences were associated with 1 yr mortality postsurgery among Veterans with LLA [9-10].

One study conducted at a nonuniversity teaching center found that the hazards of death for prosthetic users among patients who had LLA was 80 percent less than for nonprosthetic wearers after adjusting for age, diagnosis, prefunctional status, and presence of coronary artery disease [11]. However, we do not know the relationship between the receipt of a prescription for a prosthetic limb and mortality postsurgery among Veterans with LLA. We hypothesized that after controlling for various patient-, treatment-, and facility-level characteristics, receiving a prescription for a prosthetic limb would reduce the hazards of death.

\section{METHODS}

This study was approved by the institutional review boards at the University of Pennsylvania, Philadelphia, Pennsylvania; the Samuel S. Stratton Department of Veterans Affairs (VA) Medical Center (VAMC), Albany, New York; and the North Florida/South Georgia Veterans Health System (NF/SG VHS), Gainesville, Florida, as well as by the VA Research and Development Committees in Albany and Gainesville.

\section{Data Description}

Data used for this study were obtained from eight Veterans Health Administration (VHA) administrative databases: Patient Treatment File (PTF) inpatient databases (main, bed section, surgical, and procedure), two Outpatient Care Files, VA Beneficiary Identification Records Locator Subsystem (BIRLS) Death File, and National Prosthetics Patient Database (NPPD). These databases were described and applied in previous articles [8-9] and have been shown to be accurate and reliable [12-20].

In order to acquire additional information on those Veterans who obtained a prescription for a prosthetic limb in the private sector after being discharged from the VAMC where the surgical amputation occurred, the Durable Medical Equipment (DME) file from the Chronic Condition Data Warehouse of the Centers for Medicare and Medicaid Services (CMS) was used to extract receipt of a prescription for a prosthetic limb. DME is a noninstitutional claims database, which includes International Classification of Diseases-Ninth Revision-Clinical Modification (ICD-9-CM) diagnosis codes, Healthcare Common Procedure Coding System codes, and dates of service submitted by DME suppliers and providers [21]. 


\section{Study Cohort Selection}

There were 4,697 Veterans admitted for LLA from 125 VAMCs with acute discharge dates between October 1, 2002, and September 30, 2004 (fiscal years [FYs] 2003 and 2004). Cases were limited to transtibial, transfemoral, and hip disarticulation (surgical ICD-9-CM procedure codes: 84.10, 84.13-84.19, and 84.91) [22]. Our exposure timeframe was limited to $1 \mathrm{yr}$ postsurgery because typically patients only receive a prescription for a prosthetic limb within this timeframe (see "Exposure Measure" section). Prescriptions received after the $1 \mathrm{yr}$ postsurgery anniversary may be related to another amputation or may affect longer-term survival; thus, 116 subjects were removed because their prescriptions were obtained outside of the $1 \mathrm{yr}$ postsurgery criteria. One subject was removed for missing living location before hospitalization, and two subjects were excluded for unspecified amputation level. Thus, 4,578 subjects remained in the study for analyses.

\section{Exposure Measure}

Receipt of a prescription for a prosthetic limb was the time-varying independent exposure, which was measured from the amputation surgical date to $1 \mathrm{yr}$ anniversary date and obtained from the NPPD and DME files.

\section{Outcome}

The outcome was time to all-cause mortality measured from the amputation surgical date up to $3 \mathrm{yr}$. The BIRLS database was used to identify the date of death [23].

\section{Covariates Description}

\section{Patient-Level Characteristics}

The sociodemographics included age, categorized as $\leq 65$, 66 to 80 , and $\geq 81$ yr; sex; marital status (married vs unmarried); living location before hospitalization (extended care vs non-VA hospital or home); and patient residential setting (rural vs urban). Amputation level was categorized as either transtibial or transfemoral amputation. Hip disarticulations were combined with transfemoral amputation because of low prevalence $(n=33)$ and to create one "above knee" category as in our previous studies [7-10,24-35]. The new category is referred to as "transfemoral/hip disarticulation."

The contributing amputation etiologies, previously categorized by our group [9], were identified using ICD9-CM diagnosis codes from PTF main and bed section files from admission up to the surgical date and from the outpatient care files from 3 mo before hospitalization admission date.

The Elixhauser comorbidity index was our primary measure of comorbidities, identified through ICD-9-CM codes from the outpatient care files 3 mo before hospitalization and from the inpatient main and bed section files up to the surgical date [36]. Diabetes mellitus and peripheral vascular disease were categorized as amputation etiologies rather than comorbidities.

Three additional clinical covariates were controlled for because the literature showed that they may contribute to the receipt of a prescription for a prosthetic limb [8,37-47]. These clinical covariates included dementia, stroke, and vision impairment based on ICD-9-CM codes (Table 1).

Table 1.

International Classification of Diseases-Ninth Revision-Clinical Modification (ICD-9-CM) codes for dementia, stroke, and visual impairment.

\begin{tabular}{|c|c|}
\hline Condition & ICD-9-CM Codes \\
\hline Dementia & $\begin{array}{l}\text { 2900, 2901, 29010, 29011, 29012, 29013, 2902, 29020, 29021, 2903, 2904, 29040, 29041, 29042, } \\
\text { 29043, 2908, 2909, 2941, 29410, 29411, 2948, 2942, 29420, 29421, 2949, 3310, 3311, 33111, } \\
\text { 33119, 3312, 33182, 797. }\end{array}$ \\
\hline Stroke & $\begin{array}{l}\text { 430, 431, 432, 4320, 4321, 4329, 433, 43300, 43301, 43310, 43311, 43330, 43331 43380, 43381, } \\
\text { 43390, 43391, 434, 43400, 43401, 43410, 43411, 43490, 43491, 436, 438, 4380, 4381, 43810, } \\
\text { 43811, 43812, 43819, 4382, 43821, 43822, 43830, 43831, 43832, 43840, 43841, 43842, 4385, } \\
\text { 43850, 43851, 43852, 43853, 4386, 4387, 4388, 43882, 43883, 43884, 43885, 43889, 4389. }\end{array}$ \\
\hline Visual Impairment & $\begin{array}{l}\text { 36041, 36042, 36841, 36845, 36846, 36847, 369, 3690, 36900, 36901, 36902, 36903, 36904, 36905, } \\
\text { 36906, 36907, 36908, 3691, 36910, 36911, 36912, 36913, 36914, 36915, 36916, 36917, 36918, } \\
\text { 3692, 36920, 36921, 36922, 36923, 36924, 36925, 3693, 3694, 37775, 9509. }\end{array}$ \\
\hline
\end{tabular}




\section{Treatment-Level Characteristics}

Hospital events and diagnostic tests were captured from the Inpatient Procedure File from the hospital admission up to the surgical date, which included data regarding active pulmonary pathology, acute CNS, ongoing active cardiac pathology, ongoing wound problems, serious nutritional compromise, severe renal disease, and substance abuse and/or mental health issues [8]. Admission on a medical or surgical ICU anytime between the hospital admission to the surgical date and the length of stay from admission to surgery were included to approximate patient complexity.

\section{Facility-Level Characteristics}

Hospital geographic setting (rural vs urban), VAMC geographic regions (Southeast vs Northeast, Midwest, South Central, or Mountain Pacific), and hospital size estimated by total number of beds (8-126 vs 127-244, 245-362, or 363-480) were included.

\section{Other}

A year variable was added to control for any differences that may have occurred in clinical practice over the two years. Year 1 (FY 2003) included Veterans discharged from October 1, 2002, to September 30, 2003, and year 2 (FY 2004) included Veterans discharged from October 1, 2003, to September 30, 2004.

\section{Statistical Analyses}

Baseline patient-, treatment-, and facility-level characteristics were compared between Veterans who received and did not receive a prescription of prosthetic limb and between those who died and did not die within 3 yr of the surgery to provide a frequency distribution of the variables. Frequency and proportions were presented for the categorical variables, and mean \pm standard deviation were presented for the continuous variables. Chisquare tests and Student $t$-tests were used to evaluate the differences between the exposure and outcome of interest to describe the cohort.

A Cox regression model was used to estimate the hazard ratios (HRs) and 95 percent confidence intervals (CIs). Patient-, treatment-, and facility-level characteristics and year were the dependent variables. The receipt of a prescription for a prosthetic limb was added to the model as a time-dependent covariate. For Veterans who died within the 3 yr period after the surgery, the time to event variable was defined as the time between the PTF surgery date and date of death. For Veterans who did not die within the 3 yr period, time to event was defined as the time between the PTF surgery date and end of study. Variables included in the final model were selected based on clinical relevance and were only used to control for potential confounding. We used identification (ID) statement in PROC PHREG in SAS version 9.2 (SAS Institute Inc; Cary, North Carolina), and VAMC is specified as the ID variable so the correlation among Veterans from the same VAMC was accounted for. We applied criteria established by Belsley et al. [48] and used an approach illustrated by Mason [49] to test collinearity between the variables. A condition index larger than 20 is a clear indication of harmful collinearity. All statistical significance was defined by $p<0.05$, two-sided.

\section{RESULTS}

Among the total sample of 4,578 Veterans, 1,300 (28.4\%) with LLA received a prescription for a prosthetic limb within $1 \mathrm{yr}$ after the surgical amputation. Of the total sample, 2,086 (45.6\%) died within $3 \mathrm{yr}$ of the surgical anniversary. Among those who received a prescription for a prosthetic limb, only 25.2 percent died within 3 yr of the surgical anniversary. The overall average age of this cohort was $66.9 \pm 11.2 \mathrm{yr}$, and 99.1 percent were male.

Table 2 shows the unadjusted patient characteristics comparing patients who received and did not receive a prescription for a prosthetic limb within $1 \mathrm{yr}$ of the surgical amputation. Table 3 shows the unadjusted associations of patient characteristics between patients who did and did not die within $3 \mathrm{yr}$ of the surgery. Both tables provide a frequency distribution of the variables and only display variables that were significant in the Cox regression model.

There were no concerns regarding collinearity among the variables in the final model since the largest condition index was 1.91. After adjusting for patient-, treatment-, and facility-level variables and year, Veterans who received a prescription for a prosthetic limb were less likely to die after the surgery than Veterans without a prescription (HR $=0.68,95 \%$ CI $=0.60-0.77)$. Table 4 presents the HRs of other patient- and treatment-level variables significant in the Cox regression model and are only in the model for adjustment purposes. 
Table 2.

Distribution of characteristics by receipt of prescription for prosthetic limb.

\begin{tabular}{|c|c|c|c|c|}
\hline Variable & Total & $\begin{array}{c}\text { Received } \\
\text { Prescription }\end{array}$ & $\begin{array}{l}\text { Did Not Receive } \\
\text { Prescription }\end{array}$ & $p$-Value \\
\hline \multicolumn{5}{|l|}{ Patient-Level } \\
\hline \multicolumn{5}{|l|}{ Amputation Level (\%) } \\
\hline Transtibial & $2,762(60.3)$ & $1,045(37.8)$ & $1,717(62.2)$ & $<0.001$ \\
\hline Transfemoral/Hip Disarticulation & $1,816(39.7)$ & $255(14.0)$ & $1,561(86.0)$ & \\
\hline Systemic Sepsis (yes) & $516(11.3)$ & $104(20.2)$ & 412 (79.8) & $<0.001$ \\
\hline Systemic Sepsis (no) & $4,062(88.7)$ & $1,196(29.4)$ & $2,866(70.6)$ & \\
\hline \multicolumn{5}{|l|}{ Comorbidities (\%) } \\
\hline Arrhythmias (yes) & $803(17.5)$ & $177(22.0)$ & $626(78.0)$ & $<0.001$ \\
\hline Arrhythmias (no) & $3,775(82.5)$ & $1,123(29.7)$ & $2,652(70.3)$ & \\
\hline Congestive Heart Failure (no) & $3,484(76.1)$ & $1,058(30.4)$ & $2,426(69.6)$ & \\
\hline Dementia (yes) & $340(7.4)$ & $29(8.5)$ & $311(91.5)$ & $<0.001$ \\
\hline Dementia (no) & $4,238(92.6)$ & $1,271(30.0)$ & 2,967 (70.0) & \\
\hline Fluid and Electrolyte Disorders (yes) & $1,020(22.3)$ & $230(22.5)$ & 790 (77.5) & $<0.001$ \\
\hline Fluid and Electrolyte Disorders (no) & $3,558(77.7)$ & $1,070(30.1)$ & $2,488(69.9)$ & \\
\hline Liver Disease (yes) & $164(3.6)$ & $56(34.1)$ & 108 (65.9) & 0.09 \\
\hline Liver Disease (no) & $4,414(96.4)$ & $1,244(28.2)$ & $3,170(71.8)$ & \\
\hline Metastatic Cancer (yes) & $61(1.3)$ & $11(18.0)$ & $50(82.0)$ & 0.07 \\
\hline Metastatic Cancer (no) & 4,517 (98.7) & $1,289(28.5)$ & $3,228(71.5)$ & \\
\hline \multicolumn{5}{|l|}{ Treatment-Level } \\
\hline \multicolumn{5}{|l|}{ Acute Procedure Before Surgery (\%) } \\
\hline Severe Renal Disease (yes) & $218(4.8)$ & 42 (19.3) & 176 (80.7) & 0.002 \\
\hline Severe Renal Disease (no) & $4,360(95.2)$ & $1,258(28.9)$ & $3,102(71.1)$ & \\
\hline ICU Admission (yes) & $1,256(27.4)$ & 277 (22.1) & 979 (77.9) & $<0.001$ \\
\hline ICU Admission (no) & $3,322(72.6)$ & $1,023(30.8)$ & $2,299(69.2)$ & \\
\hline \multicolumn{5}{|l|}{ Other } \\
\hline Year $1(\%)$ & $2,319(50.7)$ & $657(28.3)$ & $1,662(71.7)$ & 0.92 \\
\hline Year 2 (\%) & $2,259(49.3)$ & $643(28.5)$ & $1,616(71.5)$ & \\
\hline
\end{tabular}

Note: This table shows frequency distribution of each variable by receipt of prescription for prosthetic limb. Following variables were removed from table since they were not significant in final model: sex, marital status, living location before hospitalization, patient residential setting, device infection, diabetes type I, diabetes type II, local significant infection, problems with peripheral circulation, skin breakdown, trauma, alcohol abuse, chronic blood loss anemia, coagulopathy, depression, drug abuse, other neurological disorders, paralysis, psychoses, visual impairment, weight loss, active pulmonary pathology, acute central nervous system, ongoing active cardiac pathology, serious nutritional compromise, length of stay from admission to surgery, hospital geographic setting, geographic region, and number of beds.

ICU = intensive care unit, $\mathrm{SD}=$ standard deviation. 
JRRD, Volume 52, Number 4, 2015

Table 3.

Distribution of characteristics comparing those who died with those who remained alive for 3 yr postsurgery.

\begin{tabular}{|c|c|c|c|c|}
\hline Variable & Total & Died $(n=2,086)$ & Alive $(n=2,492)$ & $p$-Value \\
\hline Receipt of Prescription for Prosthetic Limb (\%) & $1,300(28.4)$ & $328(25.2)$ & $972(74.8)$ & $<0.001$ \\
\hline No Receipt of Prescription for Prosthetic Limb (\%) & 3,278 (71.6) & $1,758(53.6)$ & $1,520(46.4)$ & \\
\hline \multicolumn{5}{|l|}{ Patient-Level } \\
\hline Age, yr (mean \pm SD) & $66.9 \pm 11.2$ & $69.7 \pm 10.8$ & $64.6 \pm 11.0$ & $<0.001$ \\
\hline \multicolumn{5}{|l|}{ Amputation Level (\%) } \\
\hline Transtibial & $2,762(60.3)$ & 1,097 (39.7) & $1,665(60.3)$ & $<0.001$ \\
\hline Transfemoral/Hip Disarticulation & $1,816(39.7)$ & $989(54.5)$ & $827(45.5)$ & \\
\hline \multicolumn{5}{|l|}{ Contributing Etiologies (\%) } \\
\hline Systemic Sepsis (yes) & $516(11.3)$ & 299 (57.9) & $217(42.1)$ & $<0.001$ \\
\hline Systemic Sepsis (no) & $4,062(88.7)$ & $1,787(44.0)$ & $2,275(56.0)$ & \\
\hline \multicolumn{5}{|l|}{ Comorbidities (\%) } \\
\hline Arrhythmias (yes) & $803(17.5)$ & $467(58.2)$ & $336(41.8)$ & $<0.001$ \\
\hline Arrhythmias (no) & $3,775(82.5)$ & 1,619 (42.9) & $2,156(57.1)$ & \\
\hline Chronic Pulmonary Disease (yes) & $223(4.9)$ & 125 (56.1) & 98 (43.9) & $<0.001$ \\
\hline Chronic Pulmonary Disease (no) & 3,655 (79.8) & $1,576(43.1)$ & 2,079 (56.9) & \\
\hline Congestive Heart Failure (yes) & $223(4.9)$ & $125(56.1)$ & 98 (43.9) & 0.001 \\
\hline Congestive Heart Failure (no) & $4,355(95.1)$ & $1,961(45.0)$ & $2,394(55.0)$ & \\
\hline Dementia (yes) & $340(7.4)$ & $227(66.8)$ & $113(33.2)$ & $<0.001$ \\
\hline Dementia (no) & $4,238(92.6)$ & 1,859 (43.9) & $2,379(56.1)$ & \\
\hline Fluid and Electrolyte Disorders (yes) & $1,020(22.3)$ & $578(56.7)$ & $442(43.3)$ & $<0.001$ \\
\hline Fluid and Electrolyte Disorders (no) & $4,471(97.7)$ & $2,053(45.9)$ & $2,418(54.1)$ & \\
\hline Liver Disease (yes) & $164(3.6)$ & $80(48.8)$ & $84(51.2)$ & 0.40 \\
\hline Liver Disease (no) & $4,414(96.4)$ & $2,006(45.4)$ & $2,408(54.6)$ & \\
\hline Metastatic Cancer (yes) & $61(1.3)$ & $50(82.0)$ & $11(18.0)$ & $<0.001$ \\
\hline Metastatic Cancer (no) & 4,517 (98.7) & $2,036(45.1)$ & $2,481(54.9)$ & \\
\hline Pulmonary Circulation Disease (yes) & $39(0.9)$ & $26(66.7)$ & $13(33.3)$ & 0.008 \\
\hline Pulmonary Circulation Disease (no) & 4,539 (99.1) & $2,060(45.4)$ & 2,479 (54.6) & \\
\hline Renal Failure (yes) & $863(18.9)$ & $530(61.4)$ & 333 (38.6) & $<0.001$ \\
\hline Renal Failure (no) & $3,715(81.1)$ & $1,556(41.9)$ & 2,159 (58.1) & \\
\hline Stroke (yes) & $373(8.1)$ & $215(57.6)$ & $158(42.4)$ & $<0.001$ \\
\hline Stroke (no) & 4,205 (91.9) & $1,871(44.5)$ & 2,334 (55.5) & \\
\hline \multicolumn{5}{|l|}{ Treatment-Level } \\
\hline \multicolumn{5}{|l|}{ Acute Procedure Before Surgery (\%) } \\
\hline Severe Renal Disease (yes) & $218(4.8)$ & $153(70.2)$ & $65(29.8)$ & $<0.001$ \\
\hline Severe Renal Disease (no) & $4,360(95.2)$ & $1,933(44.3)$ & $2,427(55.7)$ & \\
\hline ICU Admission (yes) & $1,256(27.4)$ & $688(54.8)$ & $568(45.2)$ & $<0.001$ \\
\hline ICU Admission (no) & $3,322(72.6)$ & $1,398(42.1)$ & $1,924(57.9)$ & \\
\hline \multicolumn{5}{|l|}{ Other } \\
\hline Year 1 (\%) & 2,319 (50.7) & $1,095(47.2)$ & 1,224 (52.8) & 0.02 \\
\hline Year 2 (\%) & $2,259(49.3)$ & 991 (43.9) & $1,268(56.1)$ & \\
\hline
\end{tabular}

Note: This table shows frequency distribution of each variable by 3-year mortality postsurgery. Following variables were removed from table since they were not significant in final model: sex, marital status, living location before hospitalization, patient residential setting, device infection, diabetes type I, diabetes type II, local significant infection, problems with peripheral circulation, skin breakdown, trauma, alcohol abuse, chronic blood loss anemia, coagulopathy, depression, drug abuse, other neurological disorders, paralysis, psychoses, visual impairment, weight loss, active pulmonary pathology, acute central nervous system, ongoing active cardiac pathology, serious nutritional compromise, length of stay from admission to surgery, hospital geographic setting, geographic region, and number of beds. ICU = intensive care unit, $\mathrm{SD}=$ standard deviation. 
Table 4.

Clinically based hypothesis-driven final model results.

\begin{tabular}{|c|c|c|c|}
\hline Variable & Hazard Ratio & 95\% CI & p-Value \\
\hline Receipt of Prescription for Prosthetic Limb & 0.68 & $0.60-0.77$ & $<0.001$ \\
\hline \multicolumn{4}{|l|}{ Patient-Level } \\
\hline Age $(y r)$ & 1.03 & $1.02-1.03$ & $<0.001$ \\
\hline Amputation Level (Ref: Transfemoral/Hip Disarticulation) & 1.33 & $1.21-1.46$ & $<0.001$ \\
\hline \multicolumn{4}{|l|}{ Contributing Etiologies (Ref: No) } \\
\hline Systemic Sepsis & 1.50 & $1.32-1.71$ & $<0.001$ \\
\hline \multicolumn{4}{|l|}{ Comorbidities (Ref: No) } \\
\hline Arrhythmias & 1.13 & $1.01-1.26$ & 0.03 \\
\hline Chronic Pulmonary Disease & 1.23 & $1.11-1.36$ & 0.001 \\
\hline Congestive Heart Failure & 1.33 & $1.20-1.47$ & $<0.001$ \\
\hline Dementia & 1.32 & $1.14-1.54$ & 0.003 \\
\hline Fluid and Electrolyte Disorders & 1.21 & $1.10-1.34$ & 0.002 \\
\hline Liver Disease & 1.57 & $1.24-1.98$ & 0.002 \\
\hline Metastatic Cancer & 2.86 & 2.15-3.82 & $<0.001$ \\
\hline Pulmonary Circulation Disease & 1.54 & $1.04-2.29$ & 0.03 \\
\hline Renal Failure & 1.57 & $1.39-1.76$ & $<0.001$ \\
\hline Stroke & 1.31 & $1.13-1.51$ & 0.004 \\
\hline Vascular Disease & 1.34 & $1.12-1.60$ & 0.001 \\
\hline \multicolumn{4}{|l|}{ Treatment-Level } \\
\hline \multicolumn{4}{|l|}{ Acute Procedure Before Surgery } \\
\hline Severe Renal Disease & 1.67 & $1.38-2.01$ & $<0.001$ \\
\hline ICU Admission & 1.19 & $1.08-1.31$ & 0.004 \\
\hline \multicolumn{4}{|l|}{ Other } \\
\hline Year (Ref: Year 2) & 1.20 & $1.09-1.31$ & 0.001 \\
\hline \multicolumn{4}{|c|}{$\begin{array}{l}\text { Note: Following variables were included in final model but removed from table because they were insignificant: sex, marital status, living location before hospital- } \\
\text { ization, patient residential setting, device infection, diabetes type I, diabetes type II, local significant infection, problems with peripheral circulation, skin break- } \\
\text { down, trauma, alcohol abuse, chronic blood loss anemia, coagulopathy, depression, drug abuse, other neurological disorders, paralysis, psychoses, visual } \\
\text { impairment, weight loss, active pulmonary pathology, acute central nervous system, ongoing active cardiac pathology, serious nutritional compromise, length of } \\
\text { stay from admission to surgery, hospital geographic setting, geographic region, and number of beds. } \\
\mathrm{CI}=\text { confidence interval, ICU = intensive care unit, Ref = reference. }\end{array}$} \\
\hline
\end{tabular}

\section{DISCUSSION}

Findings supported our hypothesis that Veterans with LLA who received a prescription for a prosthetic limb within $1 \mathrm{yr}$ after the surgical amputation were less likely to die within $3 \mathrm{yr}$ of the surgical amputation after controlling for patient-, treatment-, and facility-level characteristics and year. Moreover, our time-varying variable of receipt for prescription for a prosthetic limb demonstrated that the time to receipt of the prescription for a prosthetic limb was associated with lower hazards of mortality. More specifically, the earlier the prescription for a prosthetic limb was received, the lower the hazards of mortality were. This makes clinical sense because patients who do not have any postsurgery or late complications may be more likely to be fitted early with a prosthesis [50]. Those with wound infections or slow healing surgical sites, severe cardiovascular disease, local or systemic infections, or other complicating factors such as nonhealing wounds on their sound limb may see significant delays in the prosthetic fitting process. These patients may be more medically compromised in general than those who tolerate the surgery and postsurgery recovery without any complications and, thus, have a higher mortality rate in general. The early prosthetic prescription may simply be a marker for good health, and healthier people generally live longer.

However, it is critical that patients who would benefit from a prescription for a prosthetic limb obtain one as soon as they are medically stable. Postdischarge plans to assure patients return to see a prosthetic team should be a priority because intensive rehabilitation follow-up after hospital discharge could increase the prevalence of prosthetic limb users. Tracking patients via an amputation 
clinic or other rehabilitation clinic until they are ready for a prosthetic prescription might make a difference in timing of the prescription for those delayed by complicating factors and ultimately may result in greater survival.

Early fitting for a prosthesis may also provide a psychological boost to patients' motivation, thus further promoting their overall health status [51]. The perception that they are "ready" for a prosthesis and the therapy needed to be a successful prosthetic limb user can bolster a patient's confidence and sense of well-being. There needs to be emphasis on the role of social and psychological factors when evaluating and tailoring interventions to enable the optimal use of the prosthetic limb so that patients experience positive outcomes, such as increased social participation and community reintegration and higher quality of life and reduced burden on the family and community [41].

Considering psychosocial factors along with physical when prescribing prosthetic limbs and targeting rehabilitation to the specific needs of the prosthetic wearer rather than focusing solely on improving function will be beneficial to the prosthetic wearer [50]. The way persons with amputation create meaning out of their experience influences their attitude toward use and acceptance of the prosthetic limb. Users have to believe that their lives are worth living and need to be able to integrate the new device into their lives [52]. When other factors are considered, quality of life will be improved and prolong survival in general. More often than not, the psychological well-being of the individual is more important than the fact that the individual had an amputation [53].

Provision of a prosthetic limb is typically considered for community-level ambulation, but this may be an unreachable goal for many patients with LLA [4]. Safe transfers and short-distance household ambulation may be the highest functional goal achieved by many, and for others, provision of a prosthetic limb for aesthetics may be the only goal but it should not be discounted.

Prosthetic fitting rates have ranged from 50 to 90 percent among patients with transtibial or transfemoral amputations [54], while rates of actual prosthetic use have ranged from 49 to 95 percent [44,55-56]. This raises a question regarding the appropriateness and effectiveness of the prosthetic intervention. Patients who receive a prosthesis may not be using the device to its full potential [57] or appropriate rehabilitation goals may not have been clearly developed in collaboration with the patient. One study showed that Veterans who had LLA who were in possession of a prosthetic limb primarily used a wheelchair for mobility [57]. Another study demonstrated that 16 percent of nonusers never wore their prosthetic limb and 33 percent had thrown their prosthesis out during the first year [58]. Nonusers may reject a prosthetic limb because of poor fit [58] or possibly because they were not adequately trained and do not feel safe using it. It will be important to address the use and nonuse of prosthetic limbs in the future, especially because of the increasing costs of prosthetic limbs and the increasing prevalence of LLA.

There were several limitations in this study. Findings may not generalize to the entire population since this was a study that included Veterans. Moreover, the majority of Veterans are male, so it is unknown whether findings can be generalized to females. Race was not included because of the large amount of missing information in the VHA administrative databases. Also, although functional outcomes of those with hip disarticulations differ from those with transfemoral amputations, we combined the two types of amputation levels because of low prevalence among those with hip disarticulation. Furthermore, it may be that more prosthetic prescriptions are written for healthier patients or that people who are most seriously ill or disabled and likely to die are much less likely to be written a prescription. Although we have attempted to control for patient characteristics, it is difficult to fully adjust for confounding by indication in clinical research, especially using retrospective data. There may be other factors influencing the receipt of a prosthetic prescription that are also related to mortality that we were not able to identify, obtain, or differentiate in the data. Consequently, the association between receipt of a prosthetic limb and lower mortality should not be interpreted as causal. While we cannot make strict causal inferences, it is noteworthy that the statistical significance of the receipt of a prescription for a prosthetic limb remains even after accounting for many potential confounding clinical conditions.

\section{CONCLUSIONS}

Even after controlling for other factors known to be associated with mortality, such as age, amputation level, and numerous comorbidities [7,9-10,22,59-65], early receipt of a prescription for a prosthetic limb was a strong factor associated with lower mortality. Given that some patients may not be suitable, combined with the small 
cost of a prosthesis, leads to a dilemma worth exploring because of the mortality benefit demonstrated in this study among those who received a prescription for a prosthetic limb. Clinicians need to address the users' specific psychological, social, and physical needs when prescribing prosthetic limbs. Follow-up physical examinations should also resolve issues surrounding fit and delivery systems. Patient-centered care, including patient's choice, opinion, and acceptance of prosthesis, can lead to higher prosthetic use and longer survival.

\section{ACKNOWLEDGMENTS}

\section{Author Contributions:}

Study design: J. E. Kurichi, D. Xie, P. Kwong.

Analysis and statistical interpretation of the data: P. Kwong, D. Xie, J. E. Kurichi, W. B. Vogel.

Drafting of the manuscript: J. E. Kurichi.

Critical revision of the manuscript for important intellectual content: B. E. Bates, P. Kwong, D. Xie, D. Cowper Ripley, W. B. Vogel.

Obtained funding: B. E. Bates, J. E. Kurichi.

Administrative technical or material support: J. E. Kurichi.

Financial Disclosures: The authors have declared that no competing interests exist.

Funding/Support: This material was based on work supported by the National Institutes of Health (grant R01-HD042588-05A2). It was also supported by resources and the use of facilities at the University of Pennsylvania, Philadelphia, Pennsylvania; the Samuel S. Stratton VAMC, Albany, New York; and the NF/SG VHS, Gainesville, Florida. Support for VA and CMS data were provided by the VHA Office of Research and Development, Health Services Research and Development, VA Information Resource Center (project numbers SDR 02-237 and 98-004).

Additional Contributions: We would like to thank Margaret G. Stineman, MD, Center for Clinical Epidemiology and Biostatistics, University of Pennsylvania, Philadelphia, Pennsylvania, for her conceptual design of this study.

Institutional Review: This study was approved by the institutional review boards at the University of Pennsylvania, Philadelphia, Pennsylvania; the Samuel S. Stratton VAMC, Albany, New York; the NF/ SG VHS, Gainesville, Florida; and the VA Research and Development Committees in Albany and Gainesville.

Disclaimer: The opinions and conclusions of the authors are not necessarily those of the sponsoring agencies.

\section{REFERENCES}

1. Lefebvre KM, Lavery LA. Disparities in amputations in minorities. Clin Orthop Relat Res. 2011;469(7):1941-50. [PMID:21384209] http://dx.doi.org/10.1007/s11999-011-1842-x
2. Medhat A, Huber PM, Medhat MA. Factors that influence the level of activities in persons with lower extremity amputation. Rehabil Nurs. 1990;15(1):13-18.

[PMID:2300691]

http://dx.doi.org/10.1002/j.2048-7940.1990.tb01147.x

3. Horgan O, MacLachlan M. Psychosocial adjustment to lower-limb amputation: A review. Disabil Rehabil. 2004; 26(14-15):837-50. [PMID:15497913] http://dx.doi.org/10.1080/09638280410001708869

4. Pohjolainen T, Alaranta $\mathrm{H}$, Kärkkäinen M. Prosthetic use and functional and social outcome following major lower limb amputation. Prosthet Orthot Int. 1990;14(2):75-79. [PMID:2235304]

5. Schaffalitzky E, Gallagher P, Maclachlan M, Wegener ST. Developing consensus on important factors associated with lower limb prosthetic prescription and use. Disabil Rehabil. 2012;34(24):2085-94. [PMID:22494367]

http://dx.doi.org/10.3109/09638288.2012.671885

6. Hershkovitz A, Dudkiewicz I, Brill S. Rehabilitation outcome of post-acute lower limb geriatric amputees. Disabil Rehabil. 2013;35(3):221-27. [PMID:22686166] http://dx.doi.org/10.3109/09638288.2012.690818

7. Stineman MG, Kurichi JE, Kwong PL, Maislin G, Reker DM, Vogel WB, Prvu-Bettger JA, Bidelspach DE, Bates BE. Survival analysis in amputees based on physical independence grade achievement. Arch Surg. 2009;144(6): 543-51, discussion 552. [PMID:19528388] http://dx.doi.org/10.1001/archsurg.2009.37

8. Kurichi JE, Kwong PL, Reker DM, Bates BE, Marshall CR, Stineman MG. Clinical factors associated with prescription of a prosthetic limb in elderly Veterans. J Am Geriatr Soc. 2007;55(6):900-906. [PMID:17537091] http://dx.doi.org/10.1111/j.1532-5415.2007.01187.x

9. Bates B, Stineman MG, Reker DM, Kurichi JE, Kwong PL. Risk factors associated with mortality in veteran population following transtibial or transfemoral amputation. J Rehabil Res Dev. 2006;43(7):917-28. [PMID:17436177] http://dx.doi.org/10.1682/JRRD.2006.03.0030

10. Bates BE, Xie D, Kurichi JE, Cowper Ripley D, Kwong PL, Stineman MG. Revisiting risks associated with mortality following initial transtibial or transfemoral amputation. J Rehabil Res Dev. 2012;49(10):1479-92.

[PMID:23516052] http://dx.doi.org/10.1682/JRRD.2012.02.0030

11. Taylor SM, Kalbaugh CA, Blackhurst DW, Hamontree SE, Cull DL, Messich HS, Robertson RT, Langan EM 3rd, York JW, Carsten CG 3rd, Snyder BA, Jackson MR, Youkey JR. Preoperative clinical factors predict postoperative functional outcomes after major lower limb amputation: An analysis of 553 consecutive patients. J Vasc Surg. 2005;42(2):227-35. [PMID:16102618] http://dx.doi.org/10.1016/j.jvs.2005.04.015 
12. Washington DL, Sun S, Canning M. Creating a sampling frame for population-based veteran research: Representativeness and overlap of VA and Department of Defense databases. J Rehabil Res Dev. 2010;47(8):763-71.

[PMID:21110250]

http://dx.doi.org/10.1682/JRRD.2009.08.0127

13. Smith MW, Su P, Phibbs CS. Matching prosthetics order records in VA National Prosthetics Patient Database to healthcare utilization databases. J Rehabil Res Dev. 2010; 47(8):725-37. [PMID:21110248] http://dx.doi.org/10.1682/JRRD.2009.07.0098

14. Smith BM, Evans CT, Ullrich P, Burns S, Guihan M, Miskevics S, LaVela SL, Rajan S, Weaver FM. Using VA data for research in persons with spinal cord injuries and disorders: Lessons from SCI QUERI. J Rehabil Res Dev. 2010;47(8):679-88. [PMID:21110243] http://dx.doi.org/10.1682/JRRD.2009.08.0117

15. Harris AH, Reeder RN, Ellerbe L, Bowe T. Are VHA administrative location codes valid indicators of specialty substance use disorder treatment? J Rehabil Res Dev. 2010; 47(8):699-708. [PMID:21110245] http://dx.doi.org/10.1682/JRRD.2009.07.0106

16. Fischer MJ, Stroupe KT, Hynes DM, Blemur P, Sohn MW, Browning MM, Huo Z, O’Hare AM, Kaufman JS. Validation of erythropoietin use data on Medicare's End-Stage Renal Disease Medical Evidence Report. J Rehabil Res Dev. 2010;47(8):751-62. [PMID:21110249] http://dx.doi.org/10.1682/JRRD.2009.08.0108

17. Carlson KF, Nugent SM, Grill J, Sayer NA. Accuracy of external cause-of-injury coding in VA polytrauma patient discharge records. J Rehabil Res Dev. 2010;47(8):689-97. [PMID:21110244] http://dx.doi.org/10.1682/JRRD.2009.08.0118

18. Berlowitz DR, Hickey EC, Saliba D. Can administrative data identify active diagnoses for long-term care resident assessment? J Rehabil Res Dev. 2010;47(8):719-24. [PMID:21110247] http://dx.doi.org/10.1682/JRRD.2009.08.0123

19. Cowper DC, Hynes DM, Kubal JD, Murphy PA. Using administrative databases for outcomes research: Select examples from VA Health Services Research and Development. J Med Syst. 1999;23(3):249-59. [PMID:10554740] http://dx.doi.org/10.1023/A:1020579806511

20. Murphy PA, Cowper DC, Seppala G, Stroupe KT, Hynes DM. Veterans Health Administration inpatient and outpatient care data: An overview. Eff Clin Prac. 2002;5(3 Suppl):E4. [PMID:12166925]

21. Schneider K, Roozeboom M, Brenton M. Chronic condition data warehouse: Getting started with CMS Medicare administrative research files-A technical guidance paper. Version 1.0. Warrenton (VA): Buccaneer; 2011.
22. Mayfield JA, Reiber GE, Maynard C, Czerniecki JM, Caps MT, Sangeorzan BJ. Survival following lower-limb amputation in a veteran population. J Rehabil Res Dev. 2001; 38(3):341-45. [PMID:11440266]

23. Powell TM, Bagnell ME. Your "survival” guide to using time-dependent covariates. Proceedings of the SAS Global Forum; 2012 Apr 22-25; Orlando, FL.

24. Bates BE, Hallenbeck R, Ferrario T, Kwong PL, Kurichi JE, Stineman MG, Xie D. Patient-, treatment-, and facilitylevel structural characteristics associated with the receipt of preoperative lower extremity amputation rehabilitation. PM R. 2013;5(1):16-23. [PMID:22939239] http://dx.doi.org/10.1016/j.pmrj.2012.06.009

25. Bates BE, Kurichi JE, Marshall CR, Reker D, Maislin G, Stineman MG. Does the presence of a specialized rehabilitation unit in a Veterans Affairs facility impact referral for rehabilitative care after a lower-extremity amputation? Arch Phys Med Rehabil. 2007;88(10):1249-55. [PMID:17908565] http://dx.doi.org/10.1016/j.apmr.2007.06.018

26. Bates BE, Kwong PL, Kurichi JE, Bidelspach DE, Reker DM, Maislin G, Xie D, Stineman M. Factors influencing decisions to admit patients to Veterans Affairs specialized rehabilitation units after lower-extremity amputation. Arch Phys Med Rehabil. 2009;90(12):2012-18.

[PMID:19969162]

http://dx.doi.org/10.1016/j.apmr.2009.07.016

27. Kurichi JE, Ripley DC, Xie D, Kwong PL, Bates BE, Stineman MG. Factors associated with home discharge after rehabilitation among male veterans with lower extremity amputation. PM R. 2013;5(5):408-17.

[PMID:23159239]

http://dx.doi.org/10.1016/j.pmrj.2012.09.578

28. Kurichi JE, Small DS, Bates BE, Prvu-Bettger JA, Kwong PL, Vogel WB, Bidelspach DE, Stineman MG. Possible incremental benefits of specialized rehabilitation bed units among veterans after lower extremity amputation. Med Care. 2009;47(4):457-65. [PMID:19238103] http://dx.doi.org/10.1097/MLR.0b013e31818b08c6

29. Kurichi JE, Stineman MG, Kwong PL, Bates BE, Reker $\mathrm{DM}$. Assessing and using comorbidity measures in elderly veterans with lower extremity amputations. Gerontology. 2007;53(5):255-59. [PMID:17435390]

http://dx.doi.org/10.1159/000101703

30. Kurichi JE, Vogel WB, Kwong PL, Xie D, Bates BE, Stineman MG. Factors associated with total inpatient costs and length of stay during surgical hospitalization among veterans who underwent lower extremity amputation. Am J Phys Med Rehabil. 2013;92(3):203-14. [PMID:23117271] http://dx.doi.org/10.1097/PHM.0b013e31827446eb

31. Kurichi JE, Xie D, Kwong PL, Bates BE, Vogel WB, Stineman MG. Factors associated with late specialized rehabilitation 
among veterans with lower extremity amputation who underwent immediate postoperative rehabilitation. Am J Phys Med Rehabil. 2011;90(5):387-98.

[PMID:21389847]

http://dx.doi.org/10.1097/PHM.0b013e31820636c4

32. Prvu-Bettger JA, Bates BE, Bidelspach DE, Stineman MG. Short- and long-term prognosis among veterans with neurological disorders and subsequent lower-extremity amputation. Neuroepidemiology. 2009;32(1):4-10.

[PMID:18997471]

http://dx.doi.org/10.1159/000170085

33. Stineman MG, Kwong PL, Kurichi JE, Prvu-Bettger JA, Vogel WB, Maislin G, Bates BE, Reker DM. The effectiveness of inpatient rehabilitation in the acute postoperative phase of care after transtibial or transfemoral amputation: Study of an integrated health care delivery system. Arch Phys Med Rehabil. 2008;89(10):1863-72.

[PMID:18929014]

http://dx.doi.org/10.1016/j.apmr.2008.03.013

34. Stineman MG, Kwong PL, Xie D, Kurichi JE, Ripley DC, Brooks DM, Bidelspach DE, Bates BE. Prognostic differences for functional recovery after major lower limb amputation: Effects of the timing and type of inpatient rehabilitation services in the Veterans Health Administration. PM R. 2010;2(4):232-43. [PMID:20430324] http://dx.doi.org/10.1016/j.pmrj.2010.01.012

35. Zhou J, Bates BE, Kurichi JE, Kwong PL, Xie D, Stineman MG. Factors influencing receipt of outpatient rehabilitation services among veterans following lower extremity amputation. Arch Phys Med Rehabil. 2011;92(9):1455-61.

[PMID:21878217]

http://dx.doi.org/10.1016/j.apmr.2011.03.029

36. Elixhauser A, Steiner C, Harris DR, Coffey RM. Comorbidity measures for use with administrative data. Med Care. 1998;36(1):8-27. [PMID:9431328] http://dx.doi.org/10.1097/00005650-199801000-00004

37. Beekman CE, Axtell LA. Prosthetic use in elderly patients with dysvascular above-knee and through-knee amputations. Phys Ther. 1987;67(10):1510-16. [PMID:3659135]

38. Callaghan B, Condie E, Johnston M. Using the common sense self-regulation model to determine psychological predictors of prosthetic use and activity limitations in lower limb amputees. Prosthet Orthot Int. 2008;32(3):324-36. [PMID:18825576] http://dx.doi.org/10.1080/03093640802242326

39. Fletcher DD, Andrews KL, Hallett JW Jr, Butters MA, Rowland CM, Jacobsen SJ. Trends in rehabilitation after amputation for geriatric patients with vascular disease: Implications for future health resource allocation. Arch Phys Med Rehabil. 2002;83(10):1389-93.

[PMID:12370874] http://dx.doi.org/10.1053/apmr.2002.34605
40. Johannesson A, Larsson GU, Ramstrand N, Lauge-Pedersen H, Wagner P, Atroshi I. Outcomes of a standardized surgical and rehabilitation program in transtibial amputation for peripheral vascular disease: A prospective cohort study. Am J Phys Med Rehabil. 2010;89(4):293-303.

[PMID:20134308]

http://dx.doi.org/10.1097/PHM.0b013e3181cf1bee

41. Larner S, van Ross E, Hale C. Do psychological measures predict the ability of lower limb amputees to learn to use a prosthesis? Clin Rehabil. 2003;17(5):493-98.

[PMID:12952154]

http://dx.doi.org/10.1191/0269215503cr641oa

42. Leung EC, Rush PJ, Devlin M. Predicting prosthetic rehabilitation outcome in lower limb amputee patients with the functional independence measure. Arch Phys Med Rehabil. 1996;77(6):605-8. [PMID:8831480] http://dx.doi.org/10.1016/S0003-9993(96)90303-2

43. O’Neill BF, Evans JJ. Memory and executive function predict mobility rehabilitation outcome after lower-limb amputation. Disabil Rehabil. 2009;31(13):1083-91. [PMID:19280435] http://dx.doi.org/10.1080/09638280802509579

44. Schoppen T, Boonstra A, Groothoff JW, de Vries J, Göeken LN, Eisma WH. Physical, mental, and social predictors of functional outcome in unilateral lower-limb amputees. Arch Phys Med Rehabil. 2003;84(6):803-11.

[PMID:12808530]

http://dx.doi.org/10.1016/S0003-9993(02)04952-3

45. Steinberg FU, Sunwoo I, Roettger RF. Prosthetic rehabilitation of geriatric amputee patients: A follow-up study. Arch Phys Med Rehabil. 1985;66(11):742-45. [PMID:4062526]

46. Traballesi M, Brunelli S, Pratesi L, Pulcini M, Angioni C, Paolucci S. Prognostic factors in rehabilitation of above knee amputees for vascular diseases. Disabil Rehabil. 1998;20(10):380-84. [PMID:9793752] http://dx.doi.org/10.3109/09638289809166097

47. Wolf E, Lilling M, Ferber I, Marcus J. Prosthetic rehabilitation of elderly bilateral amputees. Int J Rehabil Res. 1989; 12(3):271-78. [PMID:2630503]

http://dx.doi.org/10.1097/00004356-198909000-00004

48. Belsley D, Kuh E, Welsch R. Regression diagnostics. New York (NY): John Wiley; 1980.

49. Mason G. Coping with collinearity. Can J Program Eval. 1987;2:87-93.

50. Campbell WB, Ridler BM. Predicting the use of prostheses by vascular amputees. Eur J Vasc Endovasc Surg. 1996;12(3):342-45. [PMID:8896478] http://dx.doi.org/10.1016/S1078-5884(96)80254-1

51. Fleury AM, Salih SA, Peel NM. Rehabilitation of the older vascular amputee: A review of the literature. Geriatr Gerontol Int. 2013;13(2):264-73. [PMID:23279009] http://dx.doi.org/10.1111/ggi.12016 
52. MacLachlan M, Gallagher P. Imagining the body. In: Gallagher $\mathrm{P}$, Maclachlan $\mathrm{M}$, editors. Enabling technologies: Body image and body function. Edinburgh (UK): Churchill-Livingstone; 2004.

53. Fitzpatrick MC. The psychologic assessment and psychosocial recovery of the patient with an amputation. Clin Orthop Relat Res. 1999;(361):98-107. [PMID:10212602]

54. Fletcher DD, Andrews KL, Butters MA, Jacobsen SJ, Rowland CM, Hallett JW Jr. Rehabilitation of the geriatric vascular amputee patient: A population-based study. Arch Phys Med Rehabil. 2001;82(6):776-79. [PMID:11387582] http://dx.doi.org/10.1053/apmr.2001.21856

55. Pezzin LE, Dillingham TR, Mackenzie EJ, Ephraim P, Rossbach P. Use and satisfaction with prosthetic limb devices and related services. Arch Phys Med Rehabil. 2004;85(5):723-29. [PMID:15129395] http://dx.doi.org/10.1016/j.apmr.2003.06.002

56. Reiber GE, McFarland LV, Hubbard S, Maynard C, Blough DK, Gambel JM, Smith DG. Servicemembers and veterans with major traumatic limb loss from Vietnam war and OIF/ OEF conflicts: Survey methods, participants, and summary findings. J Rehabil Res Dev. 2010;47(4):275-97. [PMID:20803399] http://dx.doi.org/10.1682/JRRD.2010.01.0009

57. Karmarkar AM, Collins DM, Wichman T, Franklin A, Fitzgerald SG, Dicianno BE, Pasquina PF, Cooper RA. Prosthesis and wheelchair use in veterans with lower-limb amputation. J Rehabil Res Dev. 2009;46(5):567-76. [PMID:19882491] http://dx.doi.org/10.1682/JRRD.2008.08.0102

58. Gauthier-Gagnon C, Grise MC, Potvin D. Predisposing factors related to prosthetic use by people with a transtibial and transfemoral amputation. J Prosthet Orthot. 1998; 10:99-109. http://dx.doi.org/10.1097/00008526-199801040-00006

59. Aulivola B, Hile CN, Hamdan AD, Sheahan MG, Veraldi JR, Skillman JJ, Campbell DR, Scovell SD, LoGerfo FW, Pomposelli FB Jr. Major lower extremity amputation: Outcome of a modern series. Arch Surg. 2004;139(4):395-99, discussion 399. [PMID:15078707]

http://dx.doi.org/10.1001/archsurg.139.4.395

60. Collins TC, Johnson M, Daley J, Henderson WG, Khuri SF, Gordon HS. Preoperative risk factors for 30-day mortality after elective surgery for vascular disease in Department of Veterans Affairs hospitals: Is race important? J Vasc Surg. 2001;34(4):634-40. [PMID:11668317]

http://dx.doi.org/10.1067/mva.2001.117329
61. Feinglass J, Pearce WH, Martin GJ, Gibbs J, Cowper D, Sorensen M, Henderson WG, Daley J, Khuri S. Postoperative and late survival outcomes after major amputation: Findings from the Department of Veterans Affairs National Surgical Quality Improvement Program. Surgery. 2001;130(1):21-29. [PMID:11436008] http://dx.doi.org/10.1067/msy.2001.115359

62. Kantonen I, Lepäntalo M, Luther M, Salenius P, Ylönen K; Finnvasc Study Group. Factors affecting the results of surgery for chronic critical leg ischemia - a nationwide survey. J Vasc Surg. 1998;27(5):940-47. [PMID:9620148] http://dx.doi.org/10.1016/S0741-5214(98)70276-9

63. O’Hare AM, Feinglass J, Reiber GE, Rodriguez RA, Daley J, Khuri S, Henderson WG, Johansen KL. Postoperative mortality after nontraumatic lower extremity amputation in patients with renal insufficiency. J Am Soc Nephrol. 2004;15(2):427-34. [PMID:14747390] http://dx.doi.org/10.1097/01.ASN.0000105992.18297.63

64. Pohjolainen T, Alaranta H. Ten-year survival of Finnish lower limb amputees. Prosthet Orthot Int. 1998;22(1):10-16. [PMID:9604271]

65. Remes L, Isoaho R, Vahlberg T, Hiekkanen H, Korhonen K, Viitanen M, Rautava P. Major lower extremity amputation in elderly patients with peripheral arterial disease: Incidence and survival rates. Aging Clin Exp Res. 2008; 20(5):385-93. [PMID:19039278] http://dx.doi.org/10.1007/BF03325142

Submitted for publication September 5, 2014. Accepted in revised form March 4, 2015.

This article and any supplementary material should be cited as follows:

Kurichi JE, Kwong P, Vogel WB, Xie D, Cowper Ripley $D$, Bates BE. Effects of prosthetic limb prescription on 3year mortality among Veterans with lower-limb amputation. J Rehabil Res Dev. 2015;52(4):385-96.

http://dx.doi.org/10.1682/JRRD.2014.09.0209

ORCID: Jibby E. Kurichi, MPH: 0000-0001-8694-355X; Barbara E. Bates, MD: 0000-0001-8077-2745

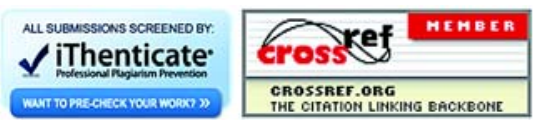

